\title{
The Effect on Video Laryngoscope on Intubation Process During Ambulance Transport
}

\author{
Bahadir Caglar and Suha Serin \\ Department of Emergency Medicine, Balikesir University, Balikesir, Turkey
}

\begin{abstract}
Objective: To compare the effects of $V L$ and $D L$ on intubation time and ease of operation in an ambulance, which is moving in real urban traffic.

Design: Comparative experimental manikin study.

Place and Duration of Study: Urla City Hospital, Izmir, Turkey, from January to May 2019.

Methodology: The paramedics were asked to intubate a standard intubation manikin and manikin with cervical collar with DL and VL in an ambulance that moving in real urban traffic. Intubation time, incisor tooth injury, and the ease of operation data were recorded.

Results: There was a statistically significant difference between the median values of DL and VL intubation times DL:18s / VL:15s in standard manikin and DL:28 s / VL:21 s in manikin with cervical collar $(p<0.001)$. When the ease of operation was evaluated, the median scores of the DL and VL Likert 5 scale were determined in the standard manikin as DL:3 / VL:5 and the manikin with collar as DL:2 / VL:4

Conclusion: VL significantly decreased the intubation time compared to DL in both normal and difficult airways. The ease of operation provided by $V L$ reduces the negative environmental factors brought by the out-of-hospital environment and ambulance movement for healthcare workers. The use of VL in limited conditions and time, reduces the intubation time and increases the ease of operation compared to DL.
\end{abstract}

Key Words: Resuscitation, Video Laryngoscope, Transport.

How to cite this article: Caglar B, Serin S. The Effect on Video Laryngoscope on Intubation Process During Ambulance Transport. J Coll Physicians Surg Pak 2020; 30(04):351-354. DOI: https://doi.org/10.29271/jcpsp.2020.04.351.

\section{INTRODUCTION}

Airway management is the "A" of emergency medicine. ${ }^{1,2}$ Oro-tracheal intubation is crucial for airway patency and ventilation. Intubation at the right time and in the right way has a direct impact on the morbidity and mortality of patients. Intubation procedures performed outside the hospital by physicians or paramedics may result in a high rate of failure. Studies have shown that unsuccessful intubation procedures reach up to $31 \%$, especially in nonhospital settings. In addition to the factors that cause difficult intubation under normal conditions such as trauma patients, short neck and obesity; the factors such as insufficient equipment brought by the external environment, a limited number of health workers, insufficient light and the inability to provide the desired position to the patient makes it more difficult to intubate outside the hospital. ${ }^{3,4}$ It is almost impossible to cope with complications of unsuccessful intubations (e.g. aspiration of stomach contents, etc.) and increases the mortality rate of the patient.

Even if health professionals receive training with simulations at regularintervals, the difficulties mentioned above are experienced.

Correspondence to: Bahadir Caglar, Department of Emergency Medicine, Balikesir University, Balikesir, Turkey

E-mail: mail@bahadircaglar.com

Received: February 29, 2020; Revised: April 19, 2020;

Accepted: May 10, 2020

DOI: https://doi.org/10.29271/jcpsp.2020.04.351
Therefore, various devices have been developed to deal with difficult airways. Video laryngoscope (VL) has come to the fore in airway management in recent years. Studies have shown that it increases the success of intubation and reduces complications related to intubation in experienced and inexperienced healthcare professionals, both in and out of the hospital. ${ }^{5-11}$ Although there are studies comparing direct laryngoscope (DL) and video laryngoscope (VL) in the literature, ${ }^{12-16}$ there are a limited number of studies comparing these two laryngoscopes within the actual ambulance in motion. Making an intubation decision in an ambulance on the move, is an indication that the patient is critical and there is not enough time. In addition, the narrowness of the environment, longitudinal, lateral and vertical accelerations brought by the movement of the ambulance and the presence of a limited number of healthcare personnel make the intubation process difficult.

In this study, the aim was to compare VL and DL on the effect on intubation time and ease of operation in an ambulance on the move in real city traffic.

\section{METHODOLOGY}

This study was planned after obtaining the necessary ethical and local permissions. Forty paramedical staff (Paramedics) from the Urla City Hospital, Izmir, Turkey, with at least 5 years of professional experience, who had used VL at least 10 times before and regularly attend simulation training, organised by the Ministry of Health, were included in the study. Paramedics were asked to intu- 
bate in an ambulance that moves on a certain route in the city traffic, where the necessary security measures were taken. They intubated the standard intubation manikin (Ambu Airway Management Trainer, Ambu, USA) placed on the stretcher with DL (Macintosh Direct Laryngoscope Set) in the first round and VL (GlideScope, Verathon, USA) in the second round. During intubation, the paramedic is in a sitting position. As soon as he took the paramedic laryngoscope in his hand, the stopwatch was operated, and it was stopped when the lungs of the manikin appeared to be ventilated by breathing with a balloon valve mask. The measured time was recorded as intubation time. Fracture of the incisor tooth during intubation was simulated by the click sound heard from the manikin. Whether the sound is heard or not is recorded. After the procedure, the paramedics were asked to evaluate the ease of operation according to the Likert 5 scale (very hard: 1, hard: 2, normal: 3, easy: 4, very easy: 5).

Later, a cervical collar was attached to the manikin to represent the difficult airway. Intubation was performed with $\mathrm{DL}$ and then VL in the same conditions and order. Intubation time click sound and ease of operation data were recorded.

SPSS 25.0 (IBM Corporation, Armonk, New York, United States) and PAST 3 (Hammer, Ø., Harper, D.A.T., Ryan, P.D. 2001. Paleontological statistics) were used in the analysis of variables. For compliance with multivariate normal distribution, it was evaluated with the Mardia test (Dornik and Hansen omnibus). In order to compare ordinary manikin and manikin with cervical collar and for comparing the calculations of intubation time/s and ease of operation of ordinary and video laryngoscope, as one of the nonparametric tests, Wilcoxon Signed Ranks Test were used with Monte Carlo results. McNemar test exact results were used for the click sound, which is a categorical variable. Quantitative variables were shown as median (1st quartile (25\%) / 3rd Quartile (75\%)) and categorical variables as $n(\%)$ in the tables. Variables were examined at $95 \%$ confidence level and $p$ value less than 0.05 was considered significant.

\section{RESULTS}

Of the 40 paramedics included in the study, there were no failed intubations or an extension of intubation time ( $>60 \mathrm{~s}$ ). There is a statistically significant difference between the median values of DL and VL and intubation time in the standard model (DL: 18s/VL: 15s). And the maximum intubation time is considered, there are as long as 43 seconds in the DL. The median times were calculated as DL: 28 s / VL: 21 s in the manikin with cervical collar $(p<0.001)$. Maximum intubation times were determined as DL: $44 \mathrm{~s}$ and VL: 27 s(Figure 1).

\section{DISCUSSION}

A successful intubation before the hospital directly affects the mortality and morbidity of the patient. In their study, Mort et al. stated that failed or prolonged intubation can cause serious complications such as hypoxemia, stomach content aspiration and heart failure. ${ }^{17}$ Failure intubation rates of up to $31 \%$ have been reported in crime scene intubations specified as non-hospital in the literature. ${ }^{2}$ However, in an ambulance on the move in traffic; narrow space, insufficient light and acceleration brought by motion make intubation more difficult. It is also almost impossible to stop the ambulance for intubation in traffic.

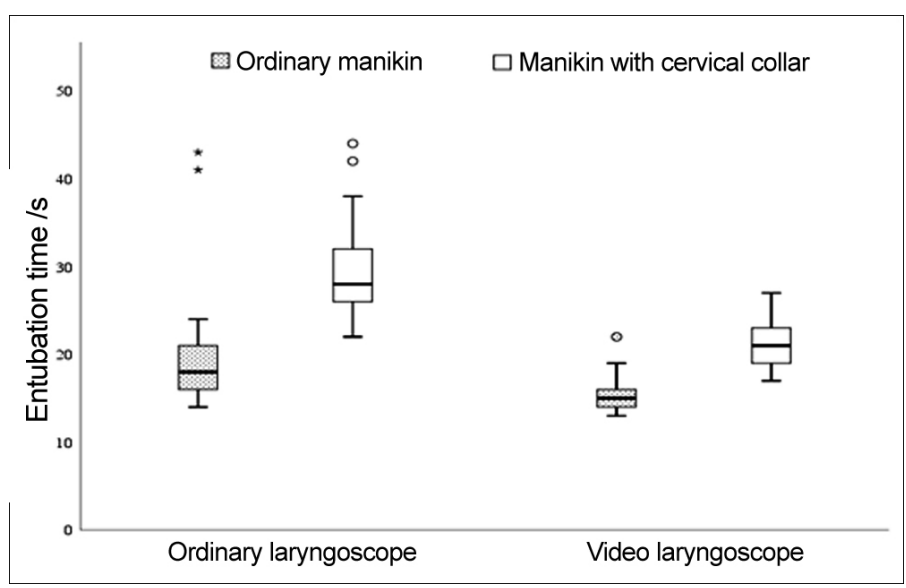

Figure 1: The click sound that we think simulates the incisor tooth injury (click +) was found between DL and VL, normal model ( $17.5 \%-10 \%)$, cervical collar model (67.5\% $-37.5 \%)$ and no statistically significant difference was found (Tablel).

Table I: Incisor tooth injury of each group.

\begin{tabular}{|c|c|c|c|}
\hline Click $(n=40)$ & $\begin{array}{c}\text { Ordinary manikin } \\
\mathrm{n}(\%)\end{array}$ & $\begin{array}{l}\text { Manikin with } \\
\text { cervical collar } \\
\quad \mathrm{n}(\%)\end{array}$ & $\begin{array}{l}\mathrm{p} \\
\text { (for ordinary-with } \\
\text { cervical collar mankin) }\end{array}$ \\
\hline $\begin{array}{l}\text { Direct laryngoscope } \\
- \\
+\end{array}$ & $\begin{array}{l}33(82.5) \\
7(17.5)\end{array}$ & $\begin{array}{l}13(32.5) \\
27(67.5)\end{array}$ & $<0.001$ \\
\hline $\begin{array}{l}\text { Video laryngoscope } \\
- \\
+\end{array}$ & $\begin{array}{c}36(90) \\
4(10)\end{array}$ & $\begin{array}{l}25(62.5) \\
15(37.5)\end{array}$ & 0.013 \\
\hline $\begin{array}{l}\text { p (for ordinal-video } \\
\text { laryngoscope) }\end{array}$ & 0.549 & 0.017 & \\
\hline \multicolumn{4}{|c|}{$\begin{array}{l}\text { When the ease of operation was evaluated, the Likert } 5 \text { scale score between } D L \text { and VL } \\
\text { was determined as the standard model (DL: } 3 / V L: 5) \text { and the cervical collar model (DL: } \\
2 / V L: 4, p<0.001 \text {, Table II). }\end{array}$} \\
\hline
\end{tabular}

Table II: Ease of operation on each group.

\begin{tabular}{|l|c|c|c|}
\hline $\begin{array}{l}\text { Ease of operation } \\
\text { (N=40) }\end{array}$ & $\begin{array}{c}\text { Ordinary manikin } \\
\text { Median (Q1. / Q3.) }\end{array}$ & $\begin{array}{c}\text { Manikin with } \\
\text { cervical collar } \\
\text { Median (Q1. / Q3.) }\end{array}$ & $\begin{array}{c}\mathbf{p} \\
\text { (for ordinary-with } \\
\text { cervical collar } \\
\text { mankin) }\end{array}$ \\
\hline Direct laryngoscope & $3(3 / 4)$ & $2(1 / 3)$ & $<0.001$ \\
\hline Video laryngoscope & $5(4 / 5)$ & $4(3 / 4)$ & $<0.001$ \\
\hline $\begin{array}{l}\text { p (for ordinal-video } \\
\text { laryngoscope) }\end{array}$ & $<0.001$ & $<0.001$ & \\
\hline
\end{tabular}

Grover et al. emphasised that although it detected statistically shorter times than the VL in terms of intubation times in the study carried out on an ambulance plane, this did not make any clinical significance. ${ }^{18}$ Guyette et al. did not detect any superiority of VL in first past success in intubation. ${ }^{19}$ However, in this study, the intubation time of VL in both normal and difficult airways decreased median values statistically significantly compared to $\mathrm{DL}$, and a decrease by half of the maximum intubation times in both airways. In previous studies, the use of VL did not make any clinical significance or had no significant superiority. ${ }^{20-22}$ However, when the intubation decision is taken in an ambulance on the move, the time gained is extremely important for other interventions to the patientin critical condition. 
When the ease of operation is evaluated, we found that $\mathrm{VL}$ provides convenience to the user in both airlines compared to DL. The ease of operation provided by VL reduces the negative environmental factors brought by the out-of-hospital environment and ambulance movement for healthcare workers.

Lecky et al. stated that the decisive role in the intubation procedure is in the practitioner. ${ }^{23}$ Clinical studies show that the use of VL positively contributes to the intubation process in experienced and inexperienced teams. ${ }^{5,24,25}$ This positive effect will be more pronounced in inexperienced healthcare professionals. In this study, there was no significant difference between laryngoscopes in terms of incisor tooth injury. The reason for the high click rate is ambulance mobility and / or paramedic origin could not be assessed.

Other advantages of using $\mathrm{VL}$ are that the image is open and recordable. The outward view will enable other healthcare professionals to participate in the procedure if intubation is not possible. The recorded intubation images can be used in medico-legal situations and for educational purposes.

Although there are studies comparing $\mathrm{DL}$ and $\mathrm{VL}$ in the literature, the number of studies performed in real traffic conditions is low. The authors think that this study is a guide in overcoming the negative factors brought by real traffic conditions.

There is no failed or prolonged ( $>60 \mathrm{~s}$ ) intubation as the study was conducted with experienced healthcare professionals. Therefore, the difference between DL and VL that may occur in inexperienced healthcare professionals has not been investigated. This work in real city traffic was done in a single center to standardize the traffic conditions (same route, same times, etc.) and may differ in non-standardized scenarios. Since it is a manikin based work, the effects of laryngoscopes on mortality and / or morbidity could not be observed. Likewise, factors that complicate intubation such as blood, secretion and steam in the airway could not be studied.

\section{CONCLUSION}

The use of video-laryngoscope in limited conditions and time, such as transport within the ambulance, reduces the intubation time and increases the ease of operation compared to normal laryngoscope.

\section{ETHICALAPPROVAL:}

This research was carried out after obtaining permission from the ethics committee of the Health Sciences University Izmir Bozyaka Training and Research Hospital.

\section{PATIENTS' CONSENT:}

Not applicable.

\section{CONFLICT OF INTEREST:}

Authors declared no conflict of interest.

\section{AUTHORS' CONTRIBUTION:}

BC: Study conception and design, acquisition of data and drafting of manuscript.

SS: Analysis and interpretation of data and critical revision.

\section{REFERENCES}

1. Kangelaris KN, Ware LB, Wang CY, Janz DR, Zhuo H, Matthay MA, et al. Timing of Intubation and clinical outcomes in adults with acute respiratory distress syndrome. Crit Care Med 2016; 44:120-9.

2. Cobas MA, De la Peña MA, Manning R, Candiotti K, Varon AJ. Prehospital intubations and mortality: A level 1 trauma center perspective. Anesth Analg 2009; 109:489-93.

3. Helm M, Hossfeld B, Schäfer S, Hoitz J, Lampl L. Factors influencing emergency intubation in the pre-hospital setting-a multicentre study in the German Helicopter Emergency Medical Service. BrJ Anaesth 2006; 96:67-71.

4. Wong KB, Lui CT, Chan WY, Lau TL, Tang SY, Tsui KL. Comparison of different intubation techniques performed inside a moving ambulance: A manikin study. Hong Kong MedJ 2014; 20:304-12.

5. Nouruzi-Sedeh P, Schumann M, Groeben H. Laryngoscopy via Macintosh blade versus GlideScope: success rate and time for endotracheal intubation in untrained medical personnel. Anesthesiology 2009; 110:32-7.

6. Aziz MF, Dillman D, Fu R, Brambrink AM. Comparative effectiveness of the C-MAC video laryngoscope versus direct laryngoscopy in the setting of the predicted difficult airway. Anesthesiology 2012; 116:629-36.

7. Robitaille $A$, Williams $S R$, Tremblay $M H$, Guilbert $F$, Thériault $M$, Drolet $P$. Cervical spine motion during tracheal intubation with manual in-line stabilisation: Direct laryngoscopy versus Glide Scope videolaryngoscopy. Anesth Analg 2008; 106:935-41

8. Malik MA, Maharaj CH, Harte BH, Laffey JG. Comparison of Macintosh, Truview EVO2, Glidescope, and Airwayscope laryngoscope use in patients with cervical spine immobilization. $\mathrm{Br} J$ Anaesth 2008; 101:723-30.

9. Michailidou M, O'Keeffe T, Mosier JM, Friese RS, Joseph B, Rhee P, et al. A comparison of video-laryngoscopy to direct laryngoscopy for the emergency intubation of trauma patients. World J Surg 2015; 39:782-8.

10. Eberlein CM, Luther IS, Carpenter TA, Ramirez LD. First-pass success intubations using video laryngoscopy versus direct laryngoscopy: A retrospective prehospital ambulance service study. Air MedJ 2019; 38:356-8.

11. Hossfeld B, Frey K, Doerges V, Lampl L, Helm M. Improvement in glottic visualisation by using the C-MAC PM video laryngoscope as a first-line device for out-of-hospital emergency tracheal intubation: An observational study. Eur J Anaesthesiol 2015; 32:425-31.

12. Szarpak L, Karczewska K, Evrin T, Kurowski A, Czyzewski L. Comparison of intubation through the McGrath MAC, GlideScope, AirTraq, and Miller Laryngoscope by paramedics during child CPR: A randomised crossover manikin trial. Am J Emerg Med $2015 ;$ 33:946-50.

13. Trimmel H, Kreutziger J, Fitzka R, Szüts S, Derdak C, Koch E, et al. Use of the GlideScope ranger video laryngoscope for emergency Intubation in the prehospital setting: A randomized control trial. Crit Care Med 2016; 44:e470-6.

14. Cortellazzi P, Caldiroli D, Byrne A, Sommariva A, Orena EF, Tramacere I. Defining and developing expertise in tracheal intubation using a GlideScope for anaesthetists with expertise in Macintosh direct laryngoscopy: an in-vivo longitudinal study. Anaesthesia 2015; 70:290-5.

15. Kriege M, Piepho T, Buggenhagen H, Noppens RR. Comparison of GlideScope Cobalt and McGrath Series 5 video laryngoscopes with direct laryngoscopy in a simulated regurgitation/aspiration scenario. Med Klin Intensivmed Notfmed 2015; 110:218-24.

16. Yildirim A, Kiraz HA, Ağaoğlu I, Akdur O. Comparison of Macintosh, McCoy and C-MAC D-Blade video laryngoscope 
intubation by prehospital emergency health workers: a simulation study. Intern Emerg Med 2017; 12:91-7.

17. Mort TC. Emergency tracheal intubation: Complications associated with repeated laryngoscopic attempts. Anesth Analg 2004; 99:607-13, table of contents.

18. Grover JM, Lubin JS, Finney AL, Tietjen K. The use of video laryngoscopy during air medical transport: A manikin study. Simul Healthc 2013; 8:229-33.

19. Guyette FX, Farrell K, Carlson JN, Callaway CW, Phrampus P. Comparison of video laryngoscopy and direct laryngoscopy in a critical care transport service. Prehosp Emerg Care 2013; 17:149-54

20. Karalapillai D, Darvall J, Mandeville J, Ellard L, Graham J, Weinberg L. A review of video laryngoscopes relevant to the intensive care unit. Indian J Crit Care Med 2014; 18:442-52.

21. Nakstad AR, Sandberg M. The GlideScope ranger video laryngoscope can be useful in airway management of entrapped patients. Acta Anaesthesiol Scand 2009; 53: 1257-61.

22. Teoh WH, Saxena S, Shah MK, Sia AT. Comparison of three videolaryngoscopes: Pentax Airway Scope, C-MAC, Glidescope $v s$ the Macintosh laryngoscope for tracheal intubation. Anaesthesia 2010; 65:1126-32.

23. Lecky F, Bryden D, Little R, Tong N, Moulton C. Emergency intubation for acutely ill and injured patients. Cochrane Database Syst Rev 2008; 2:CD001429.

24. Wayne MA, McDonnell M. Comparison of traditional versus video laryngoscopy in out-of-hospital tracheal intubation. Prehosp Emerg Care 2010; 14:278-82.

25. Silverberg MJ, Li N, Acquah SO, Kory PD. Comparison of video laryngoscopy versus direct laryngoscopy during urgent endotracheal intubation: A randomized controlled trial. Crit Care Med 2015; 43:636-41. 